This item was submitted to Loughborough's Research Repository by the author.

Items in Figshare are protected by copyright, with all rights reserved, unless otherwise indicated.

\title{
Uncertainty modelling of a suspension unit
}

PLEASE CITE THE PUBLISHED VERSION

http://pid.sagepub.com/content/219/6/755.abstract

\section{PUBLISHER}

Sage $\odot$ IMechE

VERSION

AM (Accepted Manuscript)

LICENCE

CC BY-NC-ND 4.0

REPOSITORY RECORD

Goh, Yee M., J.D. Booker, and Chris McMahon. 2019. "Uncertainty Modelling of a Suspension Unit”. figshare. https://hdl.handle.net/2134/10702. 
This item was submitted to Loughborough's Institutional Repository (https://dspace.lboro.ac.uk/) by the author and is made available under the following Creative Commons Licence conditions.

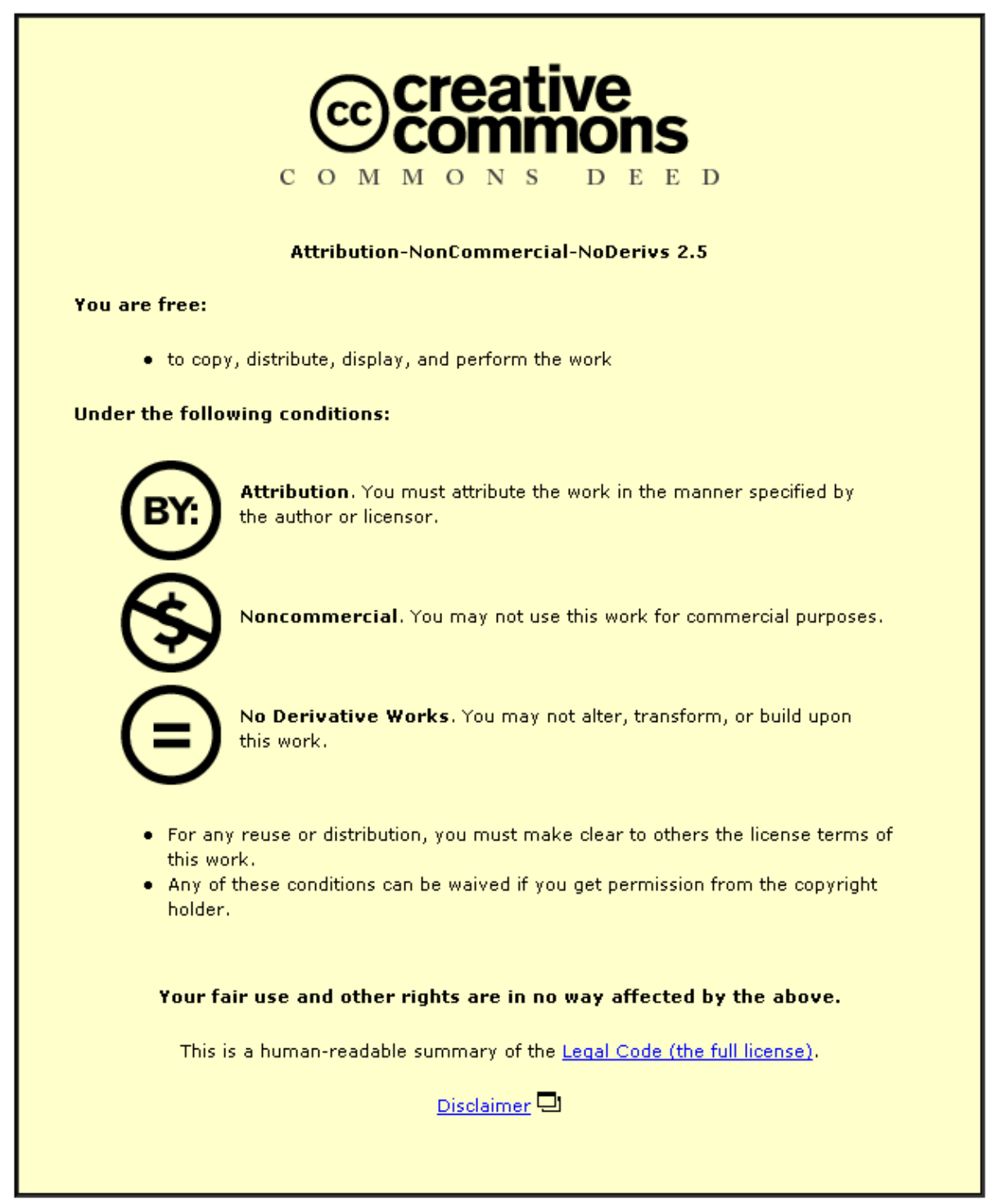

For the full text of this licence, please go to: http://creativecommons.org/licenses/by-nc-nd/2.5/ 


\title{
Uncertainty modelling of a suspension unit
}

\author{
Goh, Y M and Booker, J D \\ Department of Mechanical Engineering, University of Bristol, UK
}

\section{McMahon, C A}

Department of Mechanical Engineering, University of Bath, UK

\begin{abstract}
:
Many organisations are increasingly relying on design simulation rather than expensive and time-consuming prototype testing for product evaluation. However, uncertainties in analytical and computational methods need to be understood in order to improve confidence in their use, and models need to be validated. This paper presents a case study of a MacPherson strut automotive suspension analysis, and evaluates the uncertainties in the modelling of this complex dynamic problem using a simplified analytical model and a complex computational model. In both cases, variability in design variables is characterised using probabilistic design methods. As a first step, the model variables are described by assumed data sets, which are collated from several sources such as tolerances specified in drawings, expert opinion, published data etc. Measurement of the properties of the suspension system components is then performed (spring stiffness, damping coefficient, etc) and the statistical parameters so obtained are used in the probabilistic calculations for specified time sequences from measured test track road load data. The results are used in order to accumulate evidence of uncertainties in analytical and computational methods, to correlate predicted results to experimental data
\end{abstract}


for vehicle chassis top mount force and to derive sensitivity measures. A response surface function is approximated which is useful for parametric studies for new variants of the system studied. Sources of uncertainty in this case study and methods for improving the correlations are then suggested.

Keywords: Suspension system, probabilistic design, uncertainties, sensitivity analysis, response surface.

\section{LIST OF NOTATION}

$\begin{array}{ll}C & \text { Damping Coefficient } \\ \mathrm{C}_{\mathrm{v}} & \text { Coefficient of Variation } \\ F & \text { Force } \\ K & \text { Spring Stiffness } \\ r & \text { Correlation Coefficient } \\ t & \text { Time } \\ \text { CAE } & \text { Computer Aided Engineering } \\ \text { ADAMS } & \text { Automatic Dynamic Analysis of Mechanical Systems } \\ \text { DOE } & \text { Design of Experiment } \\ \text { MCS } & \text { Monte Carlo Simulation } \\ \text { RLD } & \text { Road Load Data } \\ \text { PDF } & \text { Probability Distributions Function } \\ \text { MBS } & \text { Multi-Body System } \\ \text { DOF } & \text { Degree of Freedom } \\ \text { DV } & \text { Design Variables }\end{array}$


FEA Finite Element Analysis

LHS Latin Hypercube Simulation

VB Visual Basic

\section{INTRODUCTION}

Many organisations are increasingly relying on design simulation rather than expensive and time-consuming prototype testing in their product development process. An important design issue concerns how engineering companies should best make use of the emerging analytical capabilities of modern Computer Aided Engineering (CAE) systems in order to improve confidence in simulation. Current rhetoric suggests that such systems are capable of simulating all of the important characteristics of engineering artefacts. However, experience with the application of CAE tools and, in particular, comparison of analytical results and experimental measurements, suggests that until we fully understand the uncertainty and variability in engineering analyses, the capabilities of analytical tools will not be adequate to allow the wholesale replacement of physical testing. An improved characterisation of uncertainties in design simulations and understanding of the physical system is therefore crucial in order to increase confidence in engineering analyses. This suggests the need for better characterisation of uncertainty in both data and modelling representations in the analytical models in order that the effect of uncertainty on the system performance is fully investigated. Understanding uncertainty and variability in engineering analyses will ultimately improve the virtual modelling of products and reduce the costs associated with physical prototyping and testing, seen as a competitive edge for the automotive industry [1]. 
Uncertainty or variability in data representation could be best facilitated through probabilistic design methods. Probabilistic design methods, as opposed to deterministic approaches, better account for variability in the analysis variables [2]. Probabilistic (or statistical) designing makes use of variability data using the same models as deterministic design, accounting for variability in the design and service related parameters by describing these as random variables determined from tests on statistically large sample sizes. We are now capable of carrying out probabilistic analysis that reflects our understanding of the uncertainties in loads, materials properties, geometry etc. In this respect, the development of a software tool called NESSUS to facilitate a wide range of probabilistic techniques in engineering applications is observed [3]

In this paper, variability in the case study design variables are characterised by probabilistic methods and propagated through analytical and computational models to evaluate the effects of variability on the system performance parameter. Two sets of variability data were used to describe the design variables, representing our understanding of the variability in these. The first set of data was estimated from published sources, manufacturing tolerances specified, the suppliers, in-house tests conducted by the collaborating company, and expert opinion only where necessary. This data set is termed the 'assumed variables'. Then, experiments were carried out on small samples of the components to verify the assumed variables for improved understanding of variability. This data set is referred to as the 'measured variables'.

Uncertainty in modelling representation on the other hand, is somewhat less established although it is widely accepted that modelling is a simplification and approximation of complex physical systems $[4,5, \mathbf{6}]$ and that model validation is important $[7, \mathbf{8}]$. In many situations, uncertainty associated with the mathematical models is not fully understood, e.g. 
invalid assumptions, violated constraints and if understood, not efficiently characterised. A better characterisation of the uncertainty in these models is therefore imperative so that the uncertainty information is readily available to engineers when solving particular problems. Recent research into uncertainty modelling using Bayesian inference, Dempster-Shafer evidence theory $[\mathbf{9}, \mathbf{1 0}]$ employ subjective judgement to account for modelling deficiencies based on expert opinion. In the current research, it is proposed that a more proactive method of systematic recording and mapping of uncertainty is required to facilitate the incorporation of uncertainty into the framework of knowledge management. A full evaluation of uncertainty in analytical and computational models however is only possible when more experimental evidence becomes available. This indicates a need for a systematic collection of validation information such as modelling error and data variability in order to facilitate better characterisation of uncertainty and variability. This paper reports part of the work - a case study illustrating the issues in a typical application - in developing a framework exploring how uncertainty in data and model representations could be characterised more effectively, given current design and manufacturing practices.

The case study - on the analysis of a front suspension system for a vehicle from an industrial collaborator - was used to demonstrate the application of probabilistic techniques to the analysis of a complex system and to explore correlation of analytical results to experimental data. The suspension system studied is of an independent MacPherson strut type. In order to accumulate evidence of uncertainties in analytical and computational methods, the suspension system was modelled with a simplified analytical approach and a commercial software package for multi-body system simulation (MSC.ADAMS), which has probabilistic design capabilities such as Design of Experiments (DOE) and Monte Carlo simulation (MCS). These models were used to predict how the variability in the input parameters affects the variability 
in predicted response of the system. The Road Load Data (RLD) measured at wheel spindles served as the forcing function in the both models. This semi-analytical approach (with deterministic load) allowed for better understanding of the model uncertainties. To draw correlation between the models and to collect uncertainty information, the predicted responses from both the simplified and ADAMS models were compared with experimental vertical top mount load data measured for the system subjected to similar road load input. The results from probabilistic analysis for both models are presented with their corresponding Probability Distribution Functions (PDF) and the discrepancies in the predicted results compared to the experimental measurement are also included to indicate the relative magnitudes of uncertainties in these models.

Sensitivity analysis was then conducted to identify critical parameters, with ranking of their contributions to the variability in the performance parameter. This information is useful to improve the efficiency of probabilistic analysis and to guide efforts in data collection. Further analysis to identify an approximation function, called a Response Surface Function (RSF) was carried out. This model is useful for fast evaluation of new variants of system studied and provides a rapid means of sensitivity analysis. Sources of uncertainty contributing to the modelling deficiency in this case study are discussed subsequently. One of the collaborating company's objectives was to predict the response of a similar rear suspension, where experimentally measured response is not available in this case. The validated model could be used to predict the response of a rear suspension unit subjected to similar road load input, with some variations in the suspension component properties. Estimates of confidence in the results and the validated model are useful for initial design evaluations of a variant system, so that prototype testing could be avoided in the early stages of the product development process. 
A full vehicle simulation can be simplified to simulation of subsystems (suspension systems, chassis/body etc.) to facilitate independent analysis and to increase computational efficiency [11]. It also results in a less complicated model and minimises the possibilities of errors and time to identify errors. Even so, the quarter or half vehicle suspension model consists of many independent parts and the equations of motion describing its dynamics are very complex. A half vehicle model was used in MSC.ADAMS while a quarter car model was used as the simplified model to describe the front suspension dynamics in this case study.

When a suspension system is subjected to Road Load Data (RLD), force will be transmitted through several components, i.e. coil spring, damper strut, jounce bumpers etc. to the top mount. The top mount is fitted to the chassis via three studs that locate in mating holes in the inner wing turret. The prediction of the mount load onto the chassis is important in vehicle design and analysis as it represents the interface of two subsystems, i.e. the load transfer from the suspension system to the car body. The performance parameter (response of interest) in this analysis is the front suspension vertical mount load.

\subsection{MSC.ADAMS Model}

MSC.ADAMS is a general-purpose Multi-Body System (MBS) simulation software which allows the simulation, understanding and quantification of the performance of mechanical systems [12]. The task of multi-body dynamics simulation is to solve the simultaneous differential equations governing the dynamics of a system. A computational model in ADAMS exists for the purpose of modelling the suspension system in the collaborating company, but is currently only used in a deterministic mode to predict the mount load. The 
system parameters are all assumed at nominal values with no variability information included. This significantly reduces the insight into effects of variability, which is important for designers to make informed decisions regarding the effects of design changes.

The ADAMS half car suspension model used in this case study consists of 37 degrees of freedom (DOF), with 32 moving parts in the model. In the model, the top mounts are fixed and the connections between parts are described by joints of various types. The model consists of a database of all the part definitions (geometry, inertial properties, characteristics, variations, etc). Nonlinear relationships describing the characteristics of the components are entered as splines in ADAMS, and instantaneous values are interpolated from spline data. The half car suspension model in ADAMS is illustrated in Figure 1.

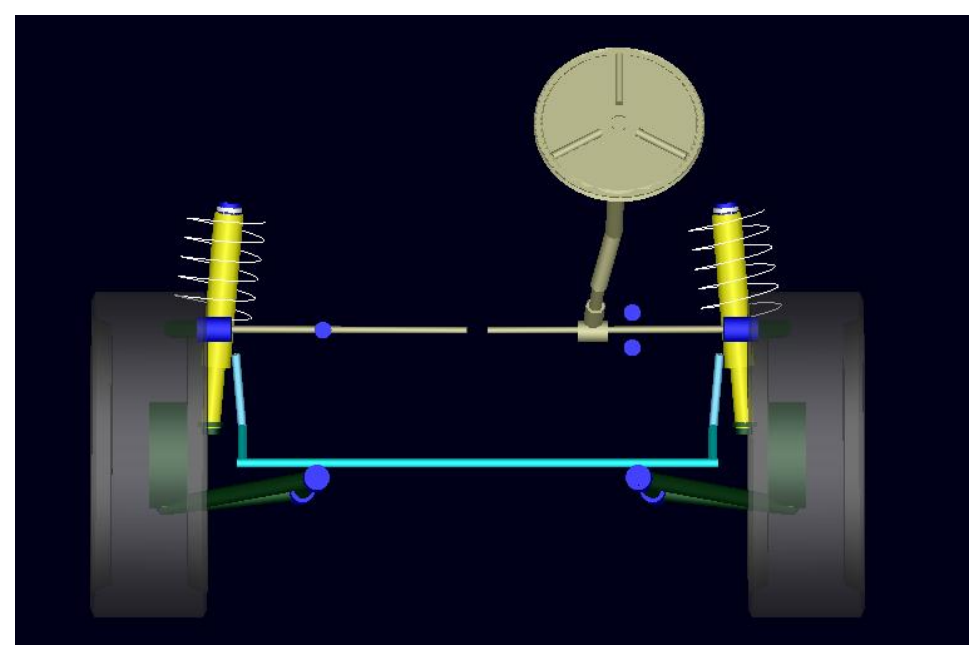

Figure 1 ADAMS Half-vehicle Model of a Car Suspension System

\subsection{Simplified Model}

The simplified model developed for this case study is a mathematical model that describes the dynamics of a quarter car suspension using a set of differential equations representing the 
equations of motion. The purpose of developing a simplified model is to draw correlation with experimental measurement and to verify its uncertainty with respect to the complex computational model in ADAMS. The simplified model also provides a 'crude' transfer function for fast sensitivity measures to guide data collection in the initial design phase to reduce computational time and resources. Generally, a two mass model is a popular representation of a quarter car system as it effectively represents the two dominant modes (sprung mass and wheel) [13]. The model consists of two lumped masses (sprung and unsprung mass), two springs (main and tyre spring rate) and a damper. In this case study, since the measured input forcing function is located at the wheel spindle, the mass that represents the wheel could be disregarded resulting in a one DOF model analysing purely the vertical load, which is the main component of load transferred onto the chassis frame. The force exerted on the wheel spindle centre is transmitted through several components to the top mount, which is constrained from movement in this model (as in the ADAMS half vehicle model). The major force components in this model are coil spring, damper, jounce and rebound bumpers. The top mount force at normal vertical wheel travel may be expressed as:

$$
F(t)=K x(t)+C x(t)
$$

where

$$
\begin{array}{lll}
F(t) & = & \text { vertical top mount force } \\
K & = & \text { spring stiffness } \\
C & = & \text { damping coefficient. }
\end{array}
$$

The dynamics of this model are different for different vertical wheel travel direction, i.e. jounce or rebound. The positions where jounce and rebound bumpers are activated are included in the model, such that the dynamics of the system changes at these two hard points, which are derived from the information obtained from drawings of the assembly and parts. 
The nonlinear force-displacement characteristics of the components are approximated by polynomials of $6^{\text {th }}$ degree. The free-body diagram used as a simplified model of the quarter car suspension in this case study is illustrated in Figure 2 along with the nomenclatures used in the diagram.

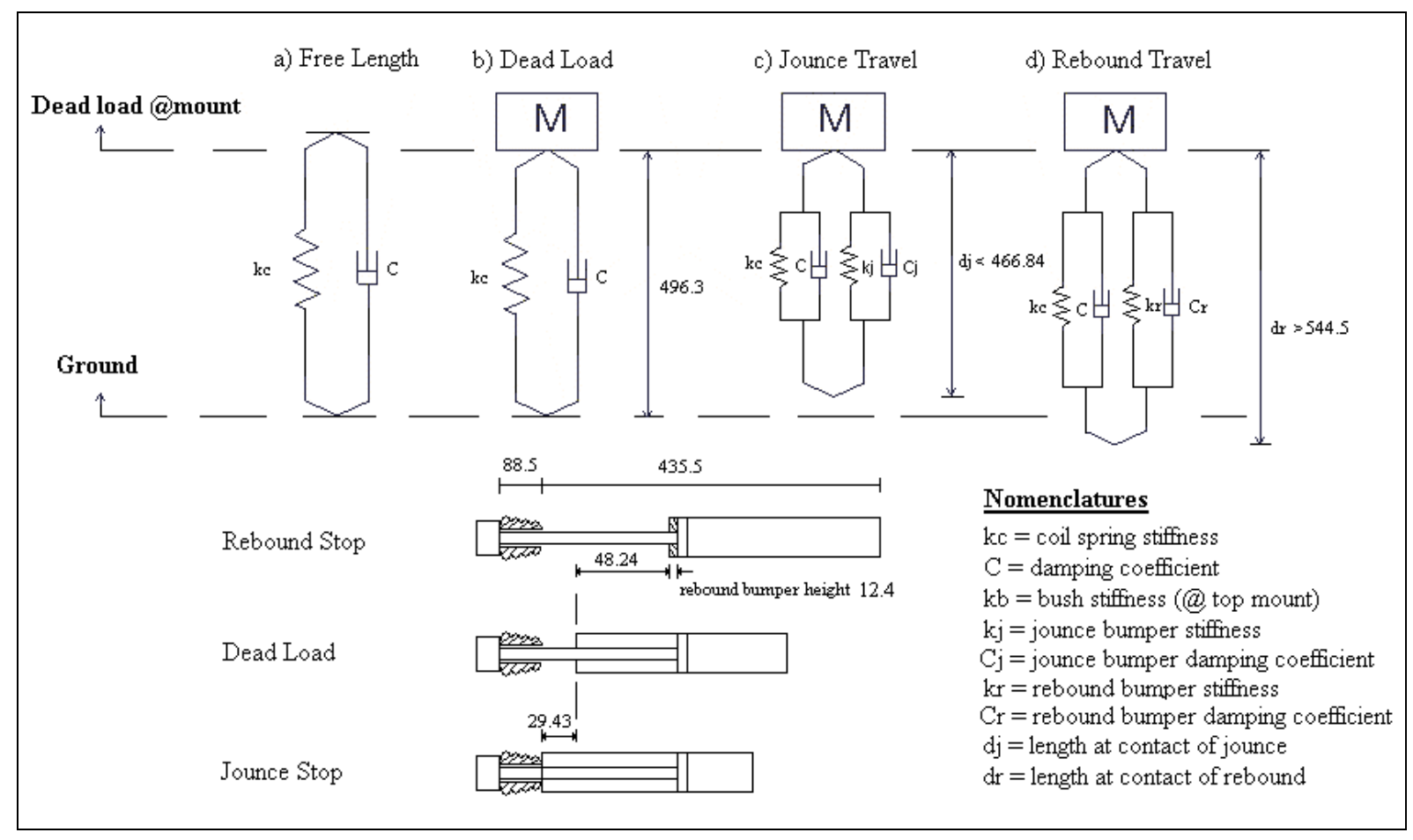

Figure 2 Free Body Diagram Quarter-vehicle Model of a Car Suspension System

Design variables are variables of interest in design analysis. In probabilistic analysis, the design variables are sampled from the probability distributions for each parameter which are either assumed or measured from testing. The most common type of probability distribution in engineering problems is the normal distribution, however Weibull and lognormal are useful in characterising skewed data as they incorporate shape parameters for more flexibility [14]. For the suspension case study, there are 8 design variables in the ADAMS model and 6 
defined in the simplified model, where bush stiffness and damping are neglected. The design variables selected in this case study are the properties of components in the suspension system. In general, they can be any parameter of interest in the model, i.e. geometrical dimensions, manufacturing tolerances, etc. Since variations in geometrical parameters and manufacturing tolerances are relatively small, they seldom contribute much to the variations in forces and are therefore considered less sensitive parameters here. One of the key criteria in probabilistic analysis is the optimum selection of design variables. Too many design variables may increase the model size enormously, while ignoring important variables may result in the loss of valuable information.

As expected, variability information is not readily available owing to the current practice of deterministic design practised in most design domains. As a first step, the variability for design variables in this case study is estimated from several sources such as tolerances specified in drawings, expert opinion, published data, etc. Table 1 gives this assumed variability in each design variable. It is assumed that all the variables are normally distributed due to lack of data availability and small sample sizes used in testing. The coefficient of variation, $\mathrm{C}_{\mathrm{v}}$ is a parameter obtained when standard deviation is divided by mean. Multiplying a design variable of constant value with a constant $\mathrm{C}_{\mathrm{v}}$ results in a constant standard deviation. However, when a nonlinear design variable is multiplied with a constant $C_{v}$, a standard deviation that is proportional to the magnitude of the design variable is obtained. Since the force-displacement relationships for the jounce and rebound bumpers and the bush at top mount are highly nonlinear, the design variables used in probabilistic analysis are their corresponding $\mathrm{C}_{\mathrm{v}}$ with normalised mean values instead of the actual design parameters, as for $\mathrm{DV}_{2}, \mathrm{DV}_{4}, \mathrm{DV}_{6}$ and $\mathrm{DV}_{8}$ in Table 1 . This random variable, described by its characteristic probability distribution, is multiplied with the nominal nonlinear relationship to produce the 
desired magnitude and variability. Therefore, a higher dispersion (increased variability) in the design variable is observed as the magnitude of the design variable increases. This situation is seen as realistic as all random functions are forced through the origin, and variability in real systems is generally proportional to its magnitude, as observed in Figure 4.

\begin{tabular}{|c|c|c|c|c|c|c|c|c|c|c|c|}
\hline \multirow{3}{*}{$\begin{array}{c}\text { COMPONENT } \\
\text { Coil spring }\end{array}$} & \multirow{3}{*}{$\begin{array}{c}\text { PARAMETER } \\
\text { Stiffness }\end{array}$} & \multirow{3}{*}{$\begin{array}{c}\text { CHARACTERISTIC } \\
\text { Linear }\end{array}$} & \multirow{2}{*}{\multicolumn{2}{|c|}{ DESIGN VARIABLE }} & \multicolumn{4}{|c|}{ ASSUMED } & \multicolumn{3}{|c|}{ MEASURED } \\
\hline & & & & & \multirow{2}{*}{\begin{tabular}{|l|} 
Mean \\
28.6
\end{tabular}} & \multirow{2}{*}{$\begin{array}{c}\text { Variation } \\
\pm 1.43\end{array}$} & \multirow{2}{*}{$\begin{array}{c}\begin{array}{c}\text { Std } \\
\text { Dev }\end{array} \\
\\
0.4767\end{array}$} & \multirow{2}{*}{$\begin{array}{c}\text { Source } \\
\text { Drawing, } \\
\text { published } \\
{[14]} \\
\end{array}$} & \multirow{2}{*}{$\frac{\text { Mean }}{28.03}$} & \multirow{2}{*}{\begin{tabular}{|c|}
$\begin{array}{c}\text { Std } \\
\text { Dev }\end{array}$ \\
0.5729 \\
\end{tabular}} & \multirow{2}{*}{$\frac{C_{v}}{2 \%}$} \\
\hline & & & $\mathrm{DV}_{1}$ & $\begin{array}{l}\text { Coil spring } \\
\text { stiffness, N/mm }\end{array}$ & & & & & & & \\
\hline \multirow{2}{*}{$\begin{array}{l}\text { Jounce } \\
\text { bumper }\end{array}$} & Stiffness & Nonlinear & $\mathrm{DV}_{2}$ & $\begin{array}{l}\text { Jounce bumper } \\
\text { stiffness scale } \\
\text { factor }\end{array}$ & 1 & $\pm 15 \%$ & 0.05 & Drawing & 1 & 0.10 & $10 \%$ \\
\hline & Damping & Linear & $\mathrm{DV}_{3}$ & $\begin{array}{l}\text { Jounce bumper } \\
\text { damping, } \\
\text { Ns/mm }\end{array}$ & 200 & $\pm 15 \%{ }^{*}$ & 10 & - & 138.93 & 18.06 & $13 \%$ \\
\hline \multirow{2}{*}{$\begin{array}{l}\text { Rebound } \\
\text { bumper }\end{array}$} & Stiffness & Nonlinear & $\mathrm{DV}_{4}$ & $\begin{array}{l}\text { Rebound } \\
\text { bumper stiffness } \\
\text { scale factor }\end{array}$ & 1 & $\pm 15 \%$ & 0.05 & - & 1 & 0.10 & $10 \%$ \\
\hline & Damping & Linear & $\mathrm{DV}_{5}$ & $\begin{array}{l}\text { Rebound } \\
\text { bumper } \\
\text { damping, } \\
\text { Ns/mm }\end{array}$ & 200 & $\pm 15 \%{ }^{*}$ & 10 & - & 138.93 & 18.06 & $13 \%$ \\
\hline \multirow{2}{*}{$\begin{array}{c}\text { Bush at } \\
\text { top mount }\end{array}$} & Stiffness & Nonlinear & $\mathrm{DV}_{6}$ & $\begin{array}{l}\text { Bush stiffness } \\
\text { scale factor }\end{array}$ & 1 & $\pm 15 \%$ & 0.05 & Drawing & 1 & 0.05 & $5 \%$ \\
\hline & Damping & Linear & $\mathrm{DV}_{7}$ & $\begin{array}{l}\text { Bush damping, } \\
\mathrm{Ns} / \mathrm{mm} \\
\end{array}$ & 2.84 & $\pm 15 \%{ }^{*}$ & 0.142 & - & 2.84 & 0.142 & $5 \%$ \\
\hline Damper ${ }^{\xi}$ & Damping & Nonlinear & $\mathrm{DV}_{8}$ & $\begin{array}{l}\text { Damping } \\
\text { coefficient scale } \\
\text { factor }\end{array}$ & 1 & $\pm 5 \%$ & 0.0167 & $\begin{array}{l}\text { Expert } \\
\text { opinion }\end{array}$ & 1 & 0.0167 & $0.02 \%$ \\
\hline
\end{tabular}

* Damping property is highly correlated to stiffness of the corresponding component

\# Assumed similar variability to jounce

$\xi$ Measured variables are not available, as assumed.

Table 1 Assumed and Measured Normal Distribution Parameters for Suspension System Elements

In order to verify the assumed variables and to substantiate our understanding of variability in design variables, small samples of the components were tested in the laboratory. These are referred to as measured variables. Variables which are not measured will remain as in assumed variables and should be verified if the corresponding components are available for testing. From the data collected, some statistical analysis was conducted to determine the best distributions that characterise each of the design variables. A statistical package called Fastfitter [15] has been used for this purpose. Based on the statistical data entered, the 
software searches through a set of distributions and gives the respective correlation coefficient, $r$ when the data is fitted with each distribution. The best-fit distribution is one with $r$ closest to 1 . The Fastfitter software also gives equivalent normal parameters for the data entered. The measured normal distribution parameters are also tabulated in Table 1. These means and standard deviations are subsequently used to pseudo-randomly generate the values according to the required sample size for each of the design variables.

\subsection{Coil Spring}

The coil spring in a suspension unit is retained in a partially compressed condition on the damper, located between a fabricated spring seat and the top mount plate. The coil spring has a linear force-displacement relationship, with assumed nominal constant spring stiffness of 28.6 N/mm. Six coil springs were tested to collect the variability information in the spring stiffness. A bi-axial Roell Amsler HCT25 tension-torsion machine was used to compress the coil spring at a constant rate of $0.08 \mathrm{~mm} / \mathrm{s}$ in the vertical direction. As more components were not available for testing, we had to proceed with the small sample size, bearing in mind that the small sample size could introduce some uncertainty in the modelling of this design variable.

\subsection{Jounce and Rebound Bumpers}

The jounce bumper is fitted to the damper to prevent shock loads when the vehicle traverses a bump, hence it only gets compressed at large positive vertical wheel travel. The jounce bumper is manufactured from polyurethane elastomer and has a highly nonlinear forcedisplacement relationship, such that it gets progressively harder to compress at extreme 
jounce travel. The jounce bumper acts in parallel to the coil spring when activated. The resultant spring characteristic then becomes nonlinear when the vertical wheel travel exceeds the impact length of the jounce bumper. Rebound bumpers, on the other hand, act in extreme rebound conditions. The rebound bumper was not available for testing, hence is modelled using the $\mathrm{C}_{\mathrm{v}}$ of the jounce bumper (assuming similar variability), but with its own nominal force-displacement relationship. The sample size available for measuring jounce bumpers' stiffness and damping was 20, which gives a reasonable approximation of the population statistics.

The test apparatus to measure the stiffness and damping properties of the jounce is shown in Figure 3. When the jounce bumper was compressed at a quasi-static rate, $0.08 \mathrm{~mm} / \mathrm{s}$, the dynamic effects of damping should have been eliminated from the model giving a nonlinear force-displacement (nonlinear spring stiffness) curve in static loading condition. The forcedisplacement data for all 20 jounce bumpers is shown in Figure 4 up to a maximum displacement of 32mm. At this displacement the best fitting PDF to the histographic data using FastFitter is a 3-parameter Weibull as shown in Figure 5. Equivalent normal mean and standard deviation data are transferred to Table 1 as a measured data set. 


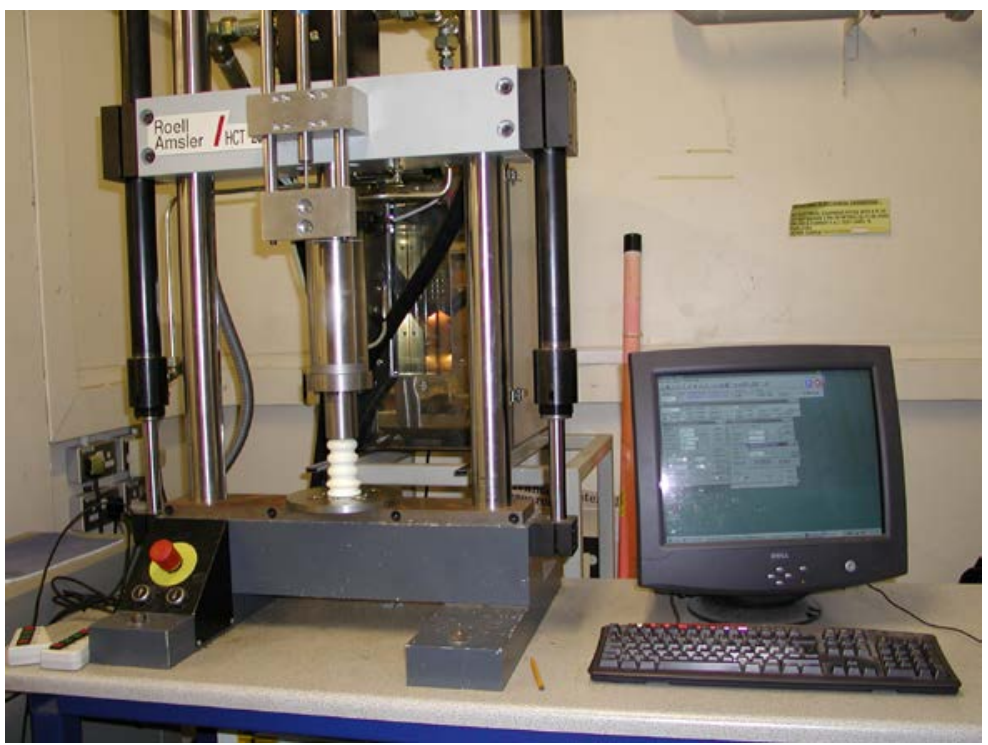

Figure 3 Test Apparatus to Measure Force-Displacement Relationship for Jounce

Bumper

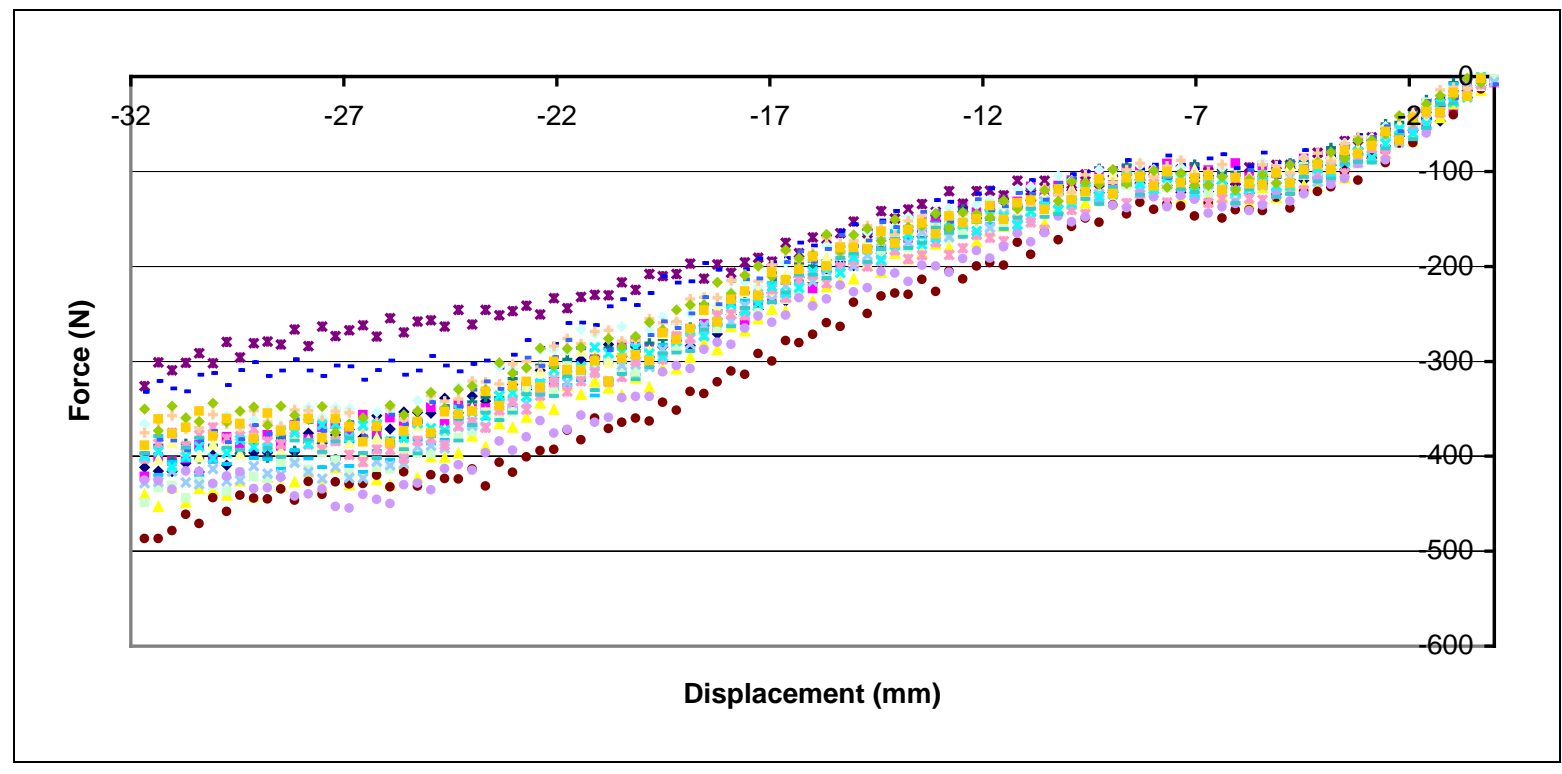

Figure 4 Quasi-static Force-Displacement Relationships for 20 Jounce Bumpers

(Loading Rate $=0.08 \mathrm{~mm} / \mathrm{s}$ ) 


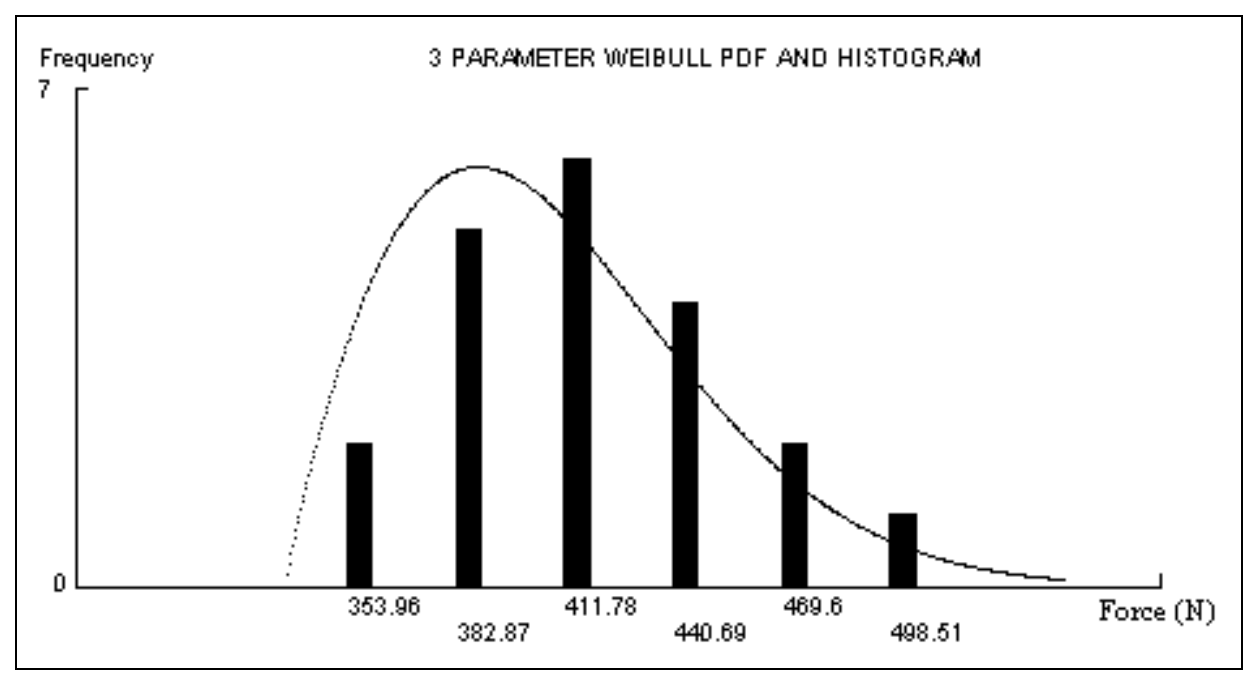

Figure 5 Best-fit Probability Distribution for 20 Jounce Bumper Force-Displacement Values at 32mm Displacement

When the forcing rate is increased, the jounce bumper damping becomes effective and this gives an increased force measured through the machine spindle, which includes both the static and dynamic loads. This increase in measured stress versus strain at higher strain rates for polyurethane elastomers is also provided in $[\mathbf{1 6}, \mathbf{1 7 ]}$. The jounce bumper was initially modelled with a classical viscoelastic Voigt model [18]. The force due to damping can be calculated from the difference between measured force (in dynamic loading) and static load obtained previously. The damping coefficient, $C$ can then be calculated from Equation 2:

$$
F_{\text {measured }}=F_{\text {static }}+F_{\text {dynamic }}=K x+C \dot{x}
$$

Not all jounce bumpers tested gave the expected damping coefficient. This may be due to the insufficiency of the model to correctly model the complex dynamic properties of polyurethane material of the jounce bumper. The stiffness and damping property of polyurethane were known to vary with temperature, strain rate, frequency, aging etc $[\mathbf{1 7}, \mathbf{1 8}]$. For the purpose of this case study, a few realistic cases are isolated to extract mean and $C_{v}$ values. These values 
were used in subsequent analysis described by measured variables. Several well established methods of modeling complex viscoelastic materials are given in [18], and other methods for example, using constitutive matrix in Finite Element Analysis (FEA) and system identification technique [16, 19] are under development.

\subsection{Bush at Top Mount and Damper}

The main function of the rubber bushes in the suspension assembly is to reduce noise and to provide improved ride quality by filtering out vibrations due to the increasing stiffness of the damper at high frequency. The force-displacement relationship for the bushes is nonlinear, its variation was not measured here but will be conducted in further tests.

The damper restricts the flow of hydraulic fluid through a series of orifices within the damper. The damping property is obtained by resistance to fluid movement. The force-velocity relationship for strut damper is also a nonlinear one. The variation in damping coefficient was not measured in this exercise but was gathered from expert opinion. The bush and damper variables in the measured data sets are similar to the assumed data set, as shown in Table 1.

\subsection{RLD and Top Mount Force Experimental Data}

The experimental measurements of RLD was available from the proving ground for a one hour period. This input force was measured at each wheel spindle centre by wheel force transducers in 3 principal axes with a sampling rate of $409.6 \mathrm{~Hz}$. The top mount force was measured by a load cell positioned between the suspension top mount plate and the chassis. In the experimental setup, the vehicle was lifted by its body and the wheels are allowed to hang freely. The signals are zeroed under this 'wheel rebound' condition. The vehicle was then 
lowered on to its wheels and dynamic signals were measured, including the effects of dead weight (preload). In this case study, only one set of experimental tower load data was measured from one vehicle, representing only one of the possible random systems. However, the measured system gives no indication of the actual PDF for this response since the actual value of each key parameter in this system was also not available. Ideally, for uncertainty evaluation purposes, the system configuration of the test vehicle has to be determined and more random physical systems should be measured. Unfortunately, this information is not available in this case study due to cost and time commitments in testing. RLD was imported to ADAMS and the simplified model to represent the forcing function for two time durations, 0 to10 seconds and 60 to 85 seconds, the latter reflecting more adverse road conditions where the jounce bumper is activated. The top mount force was also transferred to a data file for the 0 to 10 second time duration for comparison with predicted results using the various models/data sets.

\section{DETERMINATION OF TOP MOUNT FORCE STATISTICS}

\subsection{Application of Latin Hypercube Sampling to ADAMS and Simplified Models}

Owing to the long simulation time required for running an analysis in ADAMS, it is impractical to implement a Monte Carlo Simulation (MCS) routine that typically requires $10^{4}$ iterations or more. There have been many methods proposed in the literature to improve the efficiency of MCS using variance reduction techniques [20, 21, 22]. Latin Hypercube Sampling (LHS), first published by McKay [23], is one of the most popular such techniques used in reliability engineering. LHS is a stratified without replacement method and results in more even sampling throughout the sampling regions by dividing it into strata of equal 
probability. Each stratum is sampled only once, reducing the number of iterations to the number of strata specified by the user [24]. In this work, 100 samples of each design variable (DV) were pseudo-randomly generated from a LHS routine written in Visual Basic (VB), which was developed specifically for this case study application. It should be noted that some parameters may be correlated in real life, for instance the stiffness and damping of the same jounce bumper. This effect is taken into account when pairing the design variables so that a more realistic system is simulated. A correlation matrix could be specified to define correlations amongst variables using rank order suggested by Iman [25].

In ADAMS, the matrix of design variables is imported into ADAMS/Insight for probabilistic analysis. ADAMS/Insight is an extension product in MSC.ADAMS which has built-in capability to execute the MCS, but only the normal and uniform distributions could be generated automatically (in version 12.0). As mentioned previously, the normal distributions are commonly used to describe engineering variables and is the only type of distribution used to describe the design variables in this case study. However, some data are skewed in nature and need to be characterised by other types of distribution. A wider range of distributions could be generated externally to describe each variable, and the resulting matrix could be imported to ADAMS/Insight workspace. This method allows for more flexibility and control in the design variables. This method uses the same model as in a deterministic analysis, with the design variables updated at each iteration. It should be noted that only the left suspension unit parameters were varied in this analysis, all parameters on the right unit were held at their corresponding nominal mean values. This was done in order to reduce the variability caused by rolling effects, as this was not modelled in the simplified quarter car model. 
For the simplified model, variability in the design variables is taken into account by reading input files that contain the same 100 random systems, generated from the LHS subroutine and used in the ADAMS model, into the simplified model. The design variables are updated at each iteration to generate 100 responses, which gives insights into the variability in the top mount force when the system is subjected to a deterministic road load input but consists of variable system parameters. This analytical simplified model is also programmed in VB.

\subsection{Top Mount Force Prediction}

Deterministic load histories for the top mount force that were obtained from nominal systems for the simplified model, the ADAMS model and experimental measurement are shown overlaid in Figure 6 for the 0 to 10 seconds time frame. Both the ADAMS and simplified models are simulated using a time step $=0.05$ seconds, therefore higher frequency noise as observed in the experimental measurement is not present.

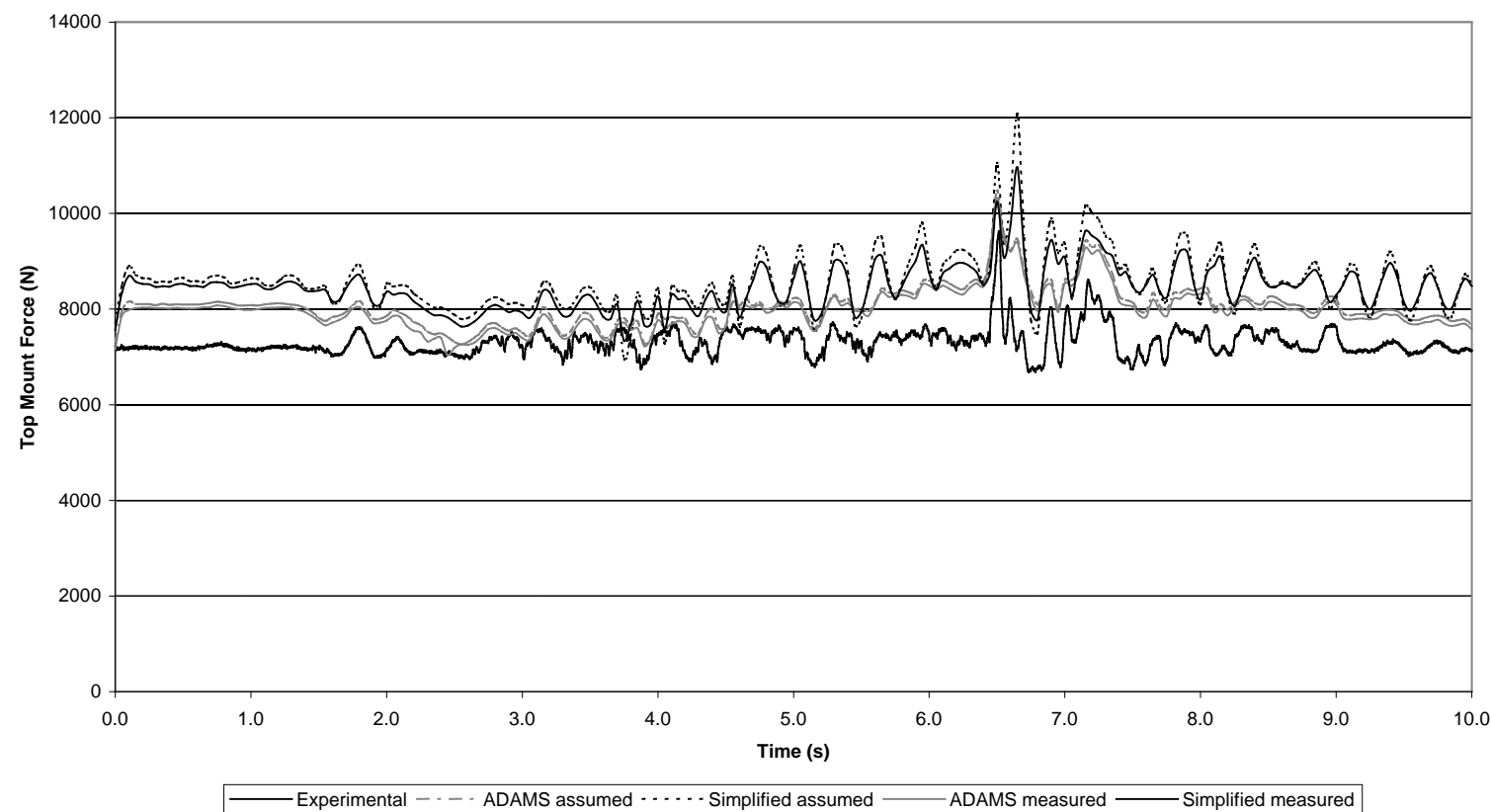




\section{Figure 6 Top Mount Force versus Time for Simplified and ADAMS Nominal System}

\section{Models Shown Against Experimental Measurement (0-10s)}

As the interest in this case study is to evaluate the effects of statistical variations on the top mount force predictions from analytical and computational models (when correlated to experimental measurement), the performance parameters are the average and range of the vertical top mount force over a stationary period:

- Average - The average top mount force is the mean of the load history over a stationary time period. The reason for using this performance parameter is to study the mean shifts between the simplified and ADAMS models and the measured experimental load history. This performance parameter indicates uncertainty and the confidence in the models.

- Range - The range of top mount force is the difference between the maximum and minimum force during the stationary time period. This performance parameter will indicate the effect of variability on the extremes, important for failure predictions and fatigue analysis. An alternative parameter could be the peak force during the same stationary time period.

The PDFs of load history averages for each model evaluated from 100 systems are presented in Figure 7. The PDFs of average top mount force predictions from the same ADAMS and simplified models with measured variables but for a different time frame (60-85s) are shown in Figure 8. The average forces obtained from nominal systems (using mean values) and the experimental measurement are indicated by arrows in the same figure. Due to the lack of knowledge about the actual design variables in the experimental system and only one physical

system tested, the actual PDF of the experimental system response is unknown. All 
comparisons are referred to this unique experimental measurement. It is observed that all the models have uncertainty of varying magnitude when compared to the experimental result.

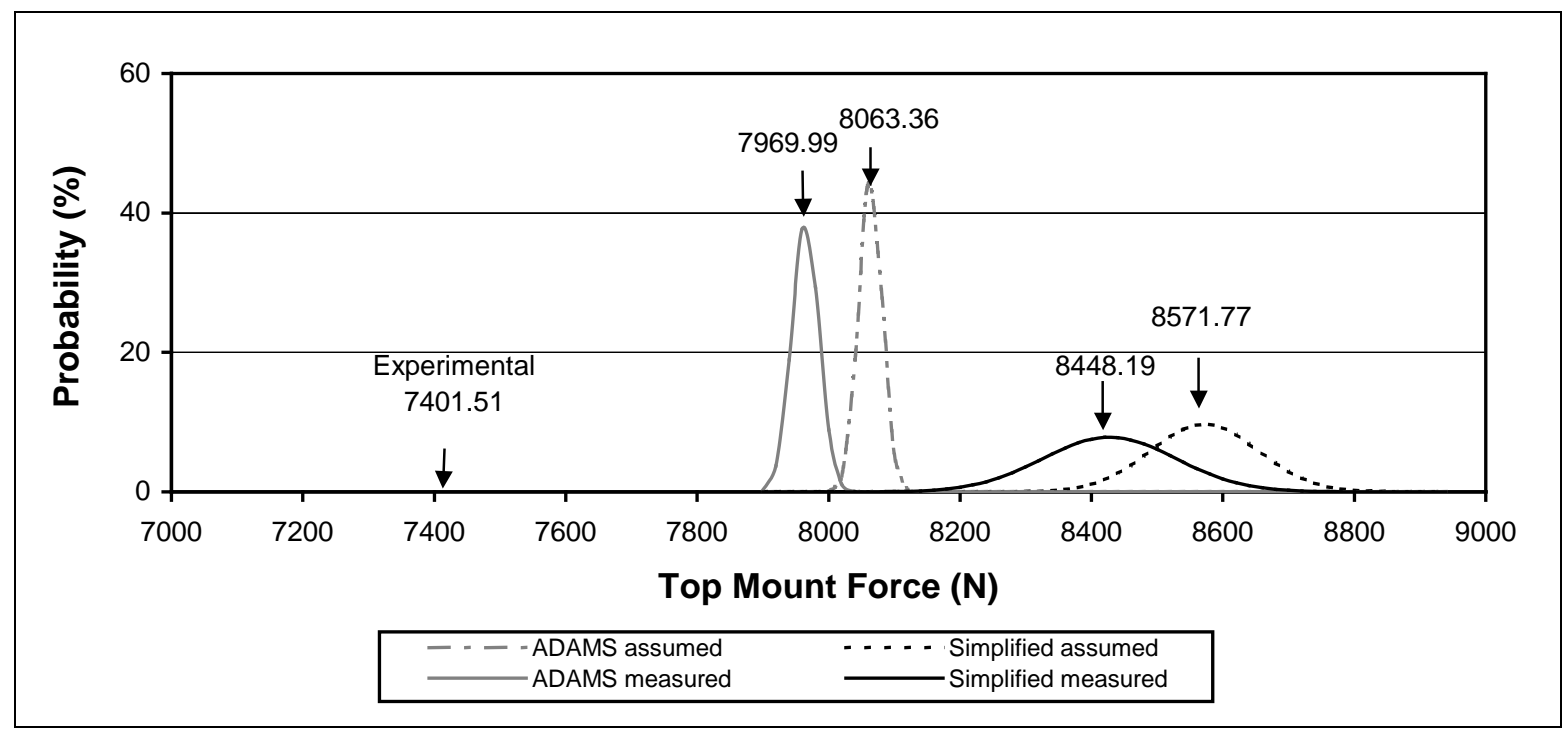

Figure 7 Top Mount Force PDFs for 100 Random Systems using Simplified and ADAMS Models and Assumed and Measured Data Compared with Experimental Measurement (0-10s)

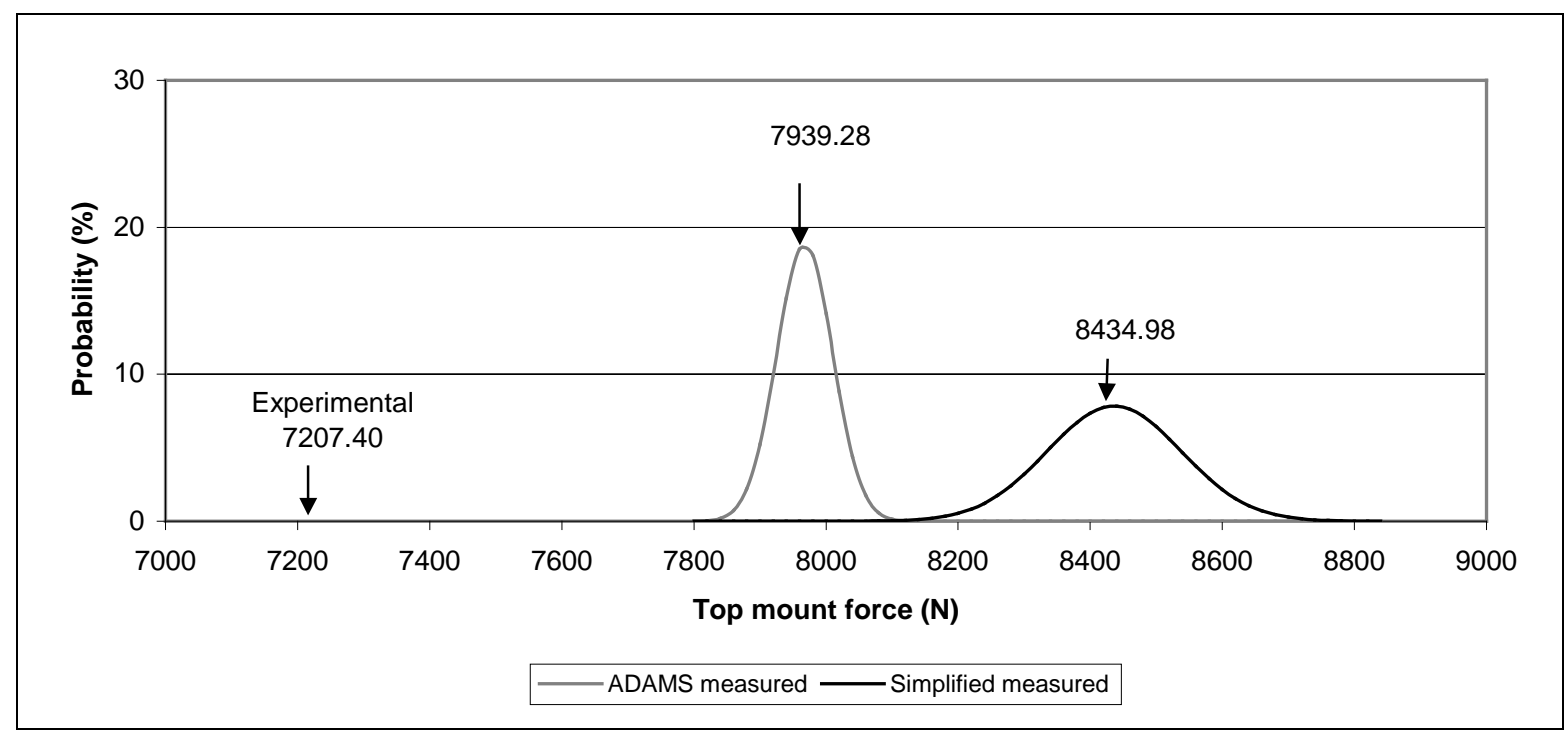


Figure 8 Top Mount Force PDFs for 100 Random Systems using Simplified and ADAMS Models and Measured Data Compared with Experimental Measurement (6085s)

Table 2 Discrepancy and coefficient of variation in the predicted average top mount force compared to unique experimental measurement

\begin{tabular}{|l|c|c|c|}
\hline \multicolumn{1}{c|}{ Model \& variable } & $\begin{array}{c}\text { Discrepancy in nominal } \\
\text { systems (\%) }\end{array}$ & $\begin{array}{c}\mathbf{C}_{\mathrm{v}} \text { (\%), } \\
\text { constant preload }\end{array}$ & $\begin{array}{c}\text { with preload as } \\
\text { variable }\end{array}$ \\
\hline Duration: 0-10s & 7.68 & 0.26 & 1.26 \\
ADAMS \& measured variables & 8.94 & 0.22 & 1.07 \\
ADAMS \& assumed variables & 14.14 & 1.21 & 2.15 \\
Simplified \& measured variables & 15.81 & 0.96 & 1.80 \\
Simplified \& assumed variables & 10.55 & 0.53 & 1.28 \\
\hline Duration: 60-85s & 17.03 & 1.21 & 1.48 \\
ADAMS \& measured variables & & & \\
\hline Simplified \& measured variables & & & \\
\hline
\end{tabular}

Discrepancies between the predicted responses of nominal systems and the unique experimental point are summarised in Table 2. The results give an indication of the magnitude of uncertainty in the predicted results due to data and modelling representations. On the model representation, it is observed that the results predicted from ADAMS model are consistently closer to the experimental point than that from simplified model. The complex description of suspension system dynamics in ADAMS has eliminated some uncertainties inherent in the one DOF simplified model. On data representation, the variability observed in the response from both models with assumed variables is only marginally lower than the response from corresponding models with measured variables. This suggests the validity of initial statistical 
data collection from several sources, without conducting any tests on specimens. However, the systematic shifts (discrepancies) between experimental measurement and models with measured variables are reduced. This represents improved understanding of the design variables, which reduces uncertainty between predicted results and the experimental measurement.

\subsection{Sensitivity Analysis (SA)}

Design of Experiments (DOE) involves a parametric study of the effects of various variables on the parameters of interest, effectively a sensitivity analysis. A sensitivity analysis is useful to give insights into the contributions of variability in each design variable to the variability in the performance parameter. The linear relationships of the performance parameters and the design variables were investigated here. The two level full factorial design is adopted in this paper for fitting a linear model required $2^{\mathrm{k}}$ runs, where $k$ is the number of design variables or factors. More comprehensive literature on this topic may be found in [26, 27]. Sensitivity analysis in ADAMS was implemented using the built-in DOE in ADAMS/Insight. There are 8 factors (corresponding to each design variable) in the ADAMS model requiring 256 experiments to fit a linear model. For the simplified model, when the variables are perturbed using the finite difference method, some rapid sensitivity relationships may be obtained. However, this method is only accurate when the variables are not correlated. Owing to the correlation between some variables in this analysis, a full DOE was conducted. The same $2^{\mathrm{k}}$ factorial design was implemented in the simplified model to obtain sensitivity measures. There are 6 design variables in the simplified model, requiring 64 experimental runs to fit a linear model. 
Sensitivity results for average top mount force to each design variable at different time frame, with different models and variable sets are summarised in Figure 9. Sensitivity results are important to guide further data collection, to evaluate impact of changes in design parameters quickly and to better understand the performance of products designed. From Figure 9 the variation in average top mount force has the highest sensitivity towards coil spring stiffness $\left(\mathrm{DV}_{1}\right)$. This is logical as the main load transfer from road input to the chassis is via the coil spring.

Figure 10 shows sensitivity results for the range of top mount force for different time frames obtained from the ADAMS model with the measured variables. Since the dynamics of the suspension are different in these time frames, the sensitivity plots show different rankings of importance. Coil spring stiffness $\left(\mathrm{DV}_{1}\right)$ remains the main factor in determining the variability of the range, while jounce bumper damping and stiffness effects $\left(\mathrm{DV}_{3}\right.$ and $\left.\mathrm{DV} \mathrm{V}_{2}\right)$ are becoming more significant during the $60-85$ s period due to more rigorous movements into the jounce bumper. This observation shows that the variability in the coil spring stiffness contributes most to the variability observed in the average and range of the top mount force and is a crucial variable to be included when a simple probabilistic analysis is carried out in early stage of design evaluations. 

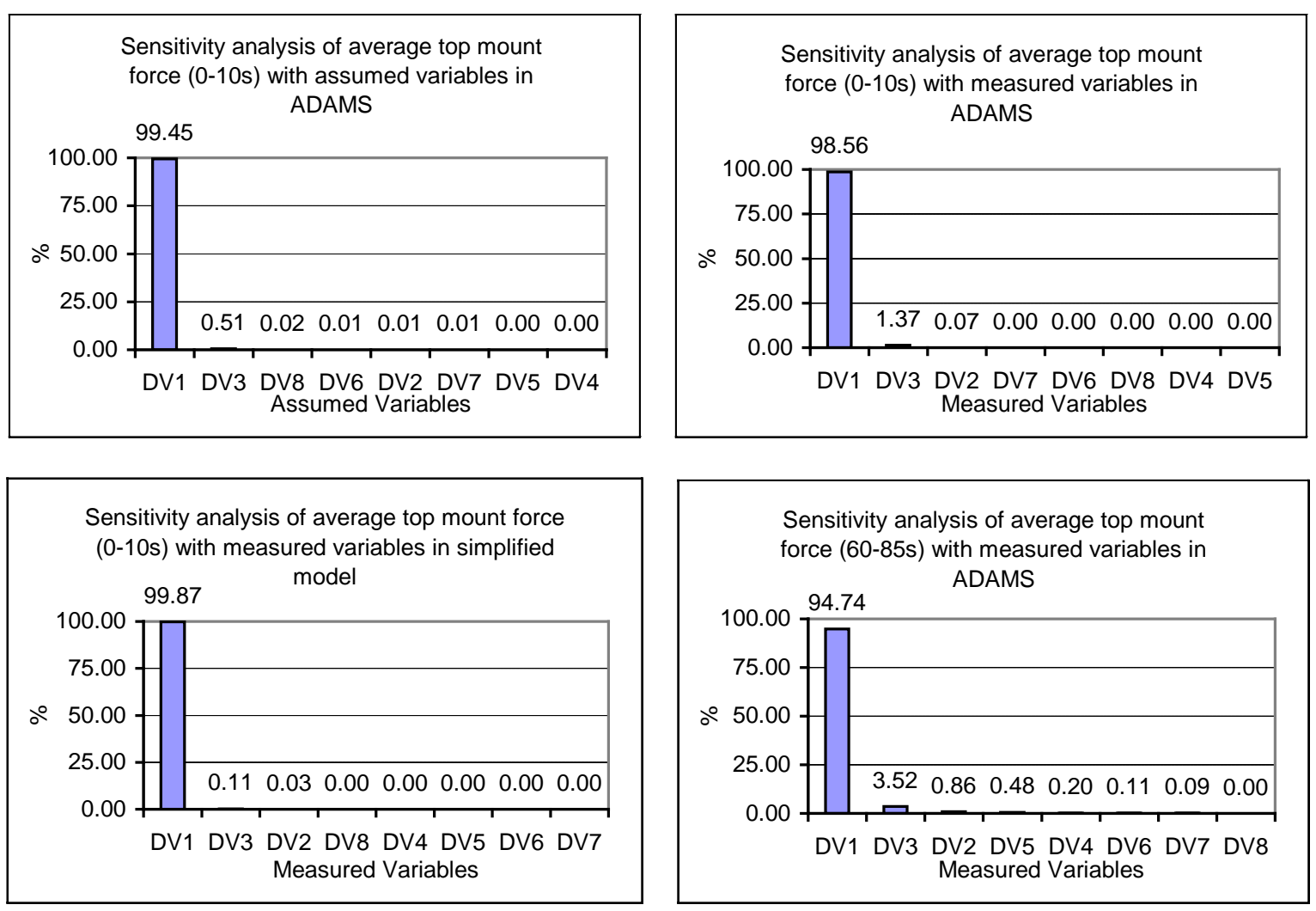

Figure 9 Sensitivity Analyses using Average Top Mount Force from Various Models,

\section{Data and Time Frames}
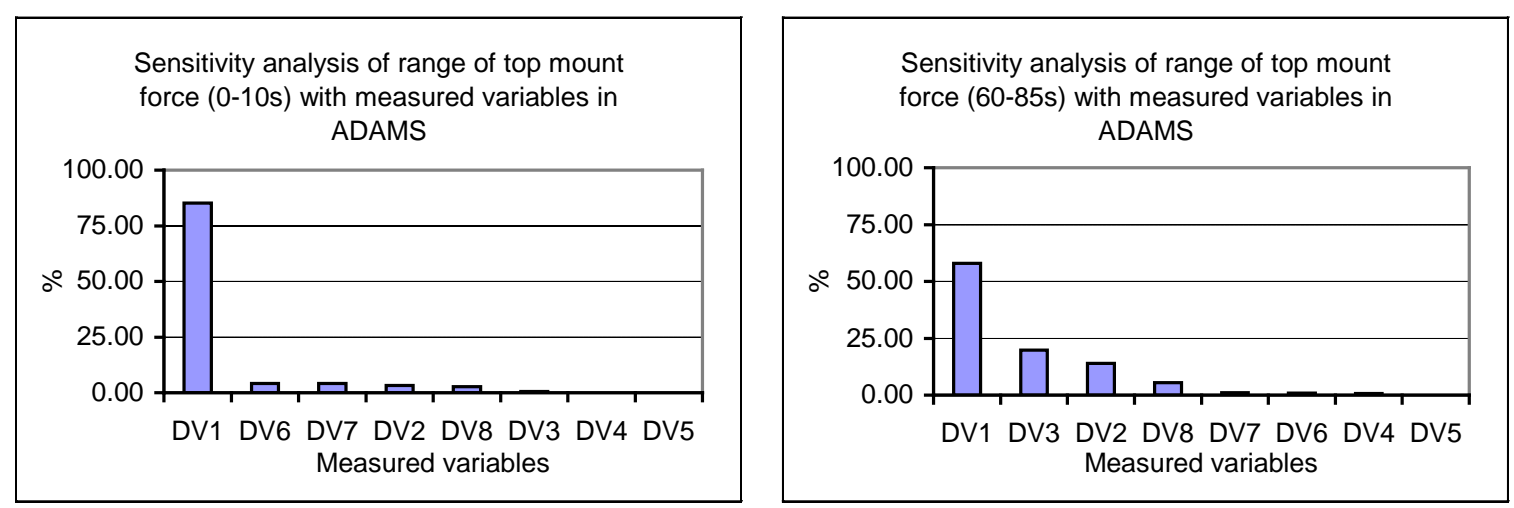

Figure 10 Sensitivity Analyses using Top Mount Force Range from ADAMS Models and Measured Data for Both Time Frames 


\subsection{Parametric Modelling of Top Mount Force}

Subsequent analysis of the DOE results leads to a parametric model for the required performance function. A parametric model, also called a response surface function is a simplified mathematical function (usually a polynomial), which approximates the actual complex performance function such as the ADAMS model. It significantly reduces the simulation time in probabilistic analysis, therefore is useful for fast evaluations of the variant of the system studied. In this case study, first-degree polynomials as functions of the design variables were obtained for the average and range performance parameter from the linear DOE analysis. The linear RSFs without cross terms (interactions) obtained from ADAMS model with measured variables for performance parameters from 0-10s are:

$$
\begin{array}{ll}
\text { Average }= & 6878.18+37.95 \mathrm{DV}_{1}+5.83 \mathrm{DV}_{2}+0.14 \mathrm{DV}_{3} \\
& +4.86 \mathrm{e}-13 \mathrm{DV}_{4}+1.64 \mathrm{e}-15 \mathrm{DV}_{5}+1.63 \mathrm{DV}_{6}+1.02 \mathrm{DV}_{7}-1.17 \mathrm{DV}_{8} \\
\text { Range } \quad & 6181.08-96.55 \mathrm{DV}_{1}-107.50 \mathrm{DV}_{2}-0.25 \mathrm{DV}_{3}+7.70 \mathrm{e}-14 \mathrm{DV}_{4} \\
& +9.51 \mathrm{e}-16 \mathrm{DV}_{5}+244.79 \mathrm{DV}_{6}+86.00 \mathrm{DV}_{7}-583.83 \mathrm{DV}_{8}
\end{array}
$$

These equations can then be used to derive an approximate variability in the performance parameter using variance analysis. The variance analysis from Taylor series approximation is:

$$
\sigma_{r}^{2}=\left(\frac{\partial r}{\partial x_{1}}\right)^{2} \sigma_{x_{1}}^{2}+\left(\frac{\partial r}{\partial x_{2}}\right)^{2} \sigma_{x_{2}}^{2}+\ldots+\left(\frac{\partial r}{\partial x_{n}}\right)^{2} \sigma_{x_{n}}^{2}
$$

The variance analysis gives $\sigma_{\text {average }}=21.90 \mathrm{~N}$, which is close to $\sigma_{\text {average }}=20.63 \mathrm{~N}$ obtained from 100 samples in ADAMS. The PDFs from the actual simulation and response surface function for 0-10s average performance parameter in ADAMS model with measured variables are illustrated in Figure 11. Since this is a linear approximation model, some uncertainty is 
inherent in the parametric model. Inclusion of cross terms and higher order terms could improve the accuracy of the parametric model, and should be included if these factors have significant contributions to the performance parameter. Time taken to evaluate the performance function (in ADAMS especially) is significantly reduced with the parametric model. This is useful to evaluate design changes quickly when one or more of the design variables changes during design iteration, however the model is only valid for the design space studied ( $\pm 3 \sigma$ from mean values in this case study).

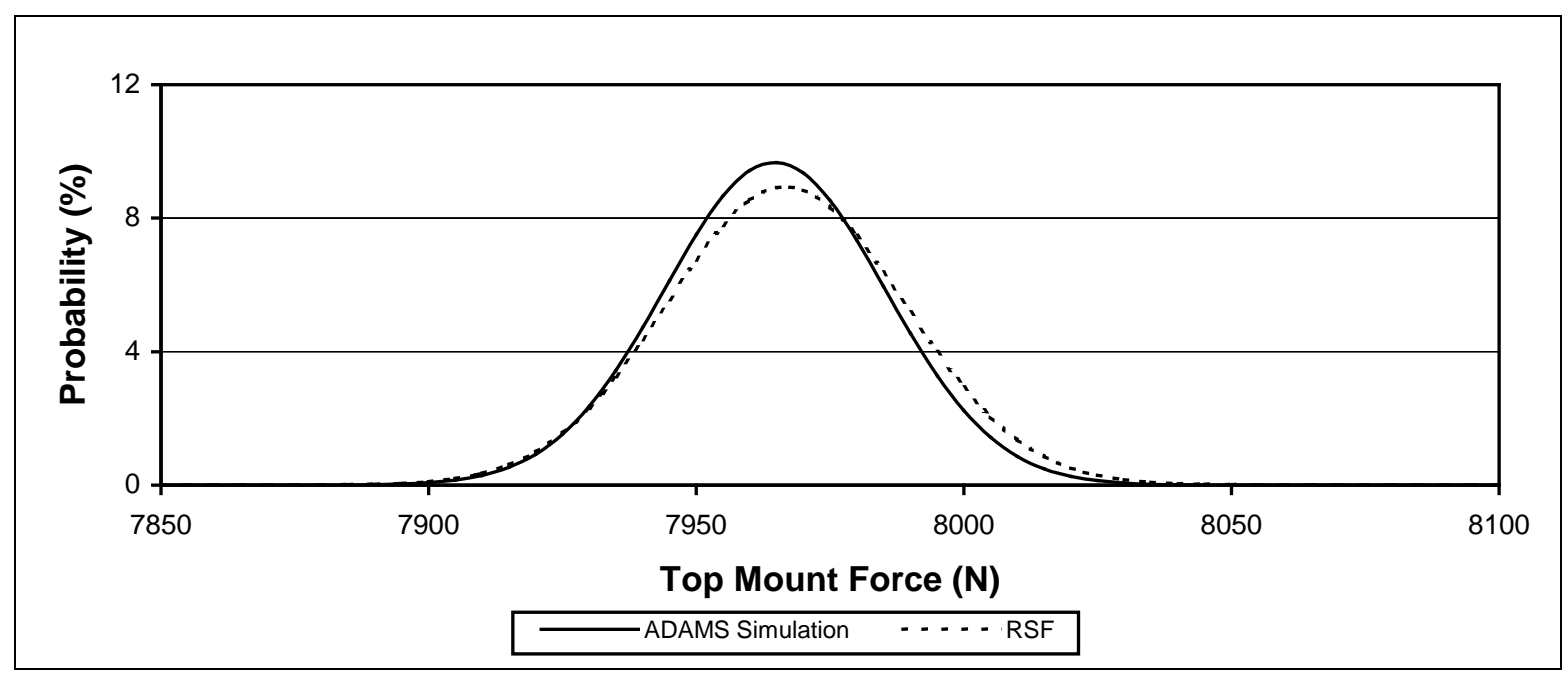

Figure 11 Probability Distributions from ADAMS Simulation using Measured Data

\section{Compared to RSF (0-10s)}

\section{DISCUSSION}

\subsection{Sources of Uncertainty}

There is an observed $7.68 \%$ discrepancy in the nominal ADAMS model and $14.14 \%$ in the nominal simplified model, both with measured variables when compared to single experimental measurement for load history average in 0-10s. This correlation suggests 
moderate confidence in each model is justified when used to predict response of suspension variants if measured load history is not available, for instance, in the use of a variant model to predict rear suspension loads. The lack of knowledge of the actual PDF in the experimental measurement of the top mount load restricted the comparison of the model predictions to a unique system performance. This unique system measured could lie anywhere within the variability range described by its PDF. The discrepancies evaluated based on this unique experimental point given in Table 2 served as an indication of the relative magnitude of uncertainties in the corresponding data and modelling representations. Although the test vehicle should not be assumed as representative of a mean value, it could be concluded that the correlations will improve if this unique system was a 'lower bound' and vice versa if it was an 'upper bound'.

The variability in the performance parameter predicted, $\mathrm{C}_{\mathrm{v}}$ is also tabulated in Table 2 . It is observed that $C_{v}$ values in predicted average response from the simplified model is generally higher compared to the ADAMS model, even though identical variability in the input data is propagated through the models, except for the omission of bush stiffness and damping in the simplified model. These factors are however, confirmed insensitive in the sensitivity results from ADAMS. Statistical test of variance, F-tests conducted suggest different variances for both models with assumed and measured variables, for the two time frames. Sensitivity results show that the coil spring stiffness $\left(\mathrm{DV}_{1}\right)$ contributes most to the variability observed in the performance parameters studied in this paper. Since the preload is highly determined by the coil spring stiffness, including variability in preload affects the variability in the performance parameter. Figure 12 illustrates the PDFs of the average top mount force with preload included as a variable. $\mathrm{C}_{\mathrm{v}}$ values in Table 2 show increment in the respective models when preload is a variable, but the differences between simplified and ADAMS models have 
been reduced. For 60-85s with variable preload, $\mathrm{C}_{\mathrm{v}}$ for both models with measured variables is found to be the closest $(\mathrm{F}=1.51)$. F-tests show that the variances from these two models (60-85s) are not statistically different at 99\% confidence level $(\mathrm{F}<1.60)$.

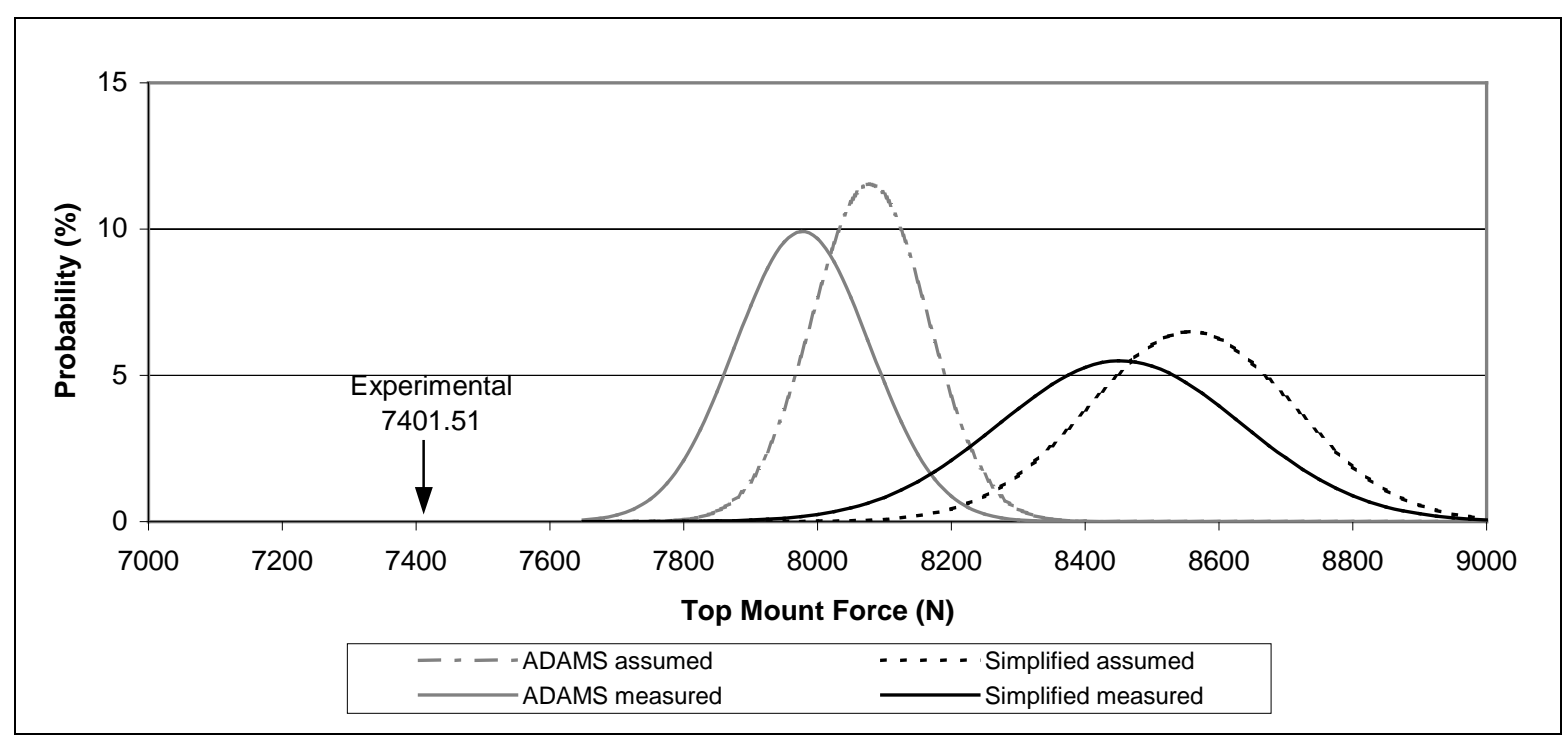

Figure 12 Top Mount Force PDFs for 100 Random Systems using Simplified and ADAMS Models and Assumed and Measured Data Compared with Experimental Measurement (0-10s), with variable preload

In order to explain the systematic shifts observed between predicted results and the experimental measurement, several sources of uncertainty in ADAMS and simplified models are outlined in the following sections. With the sources of uncertainty identified and systematically mapped throughout the analytical activities, modelling errors and the contribution of each assumption or simplification towards the observed discrepancy between experimental and model predictions could be better characterised. This improved understanding of uncertainties in data and model representations will ultimately increase confidence in simulation based analysis to achieve reliable virtual modelling of products. 


\subsubsection{ADAMS Model}

In this analysis, only variations in the left suspension parameters are included whereas the right suspension parameters assumed nominal values. In reality however, the corresponding parameters on the right suspension vary randomly as well as the left suspension. Variable rolling effects resulting from random pairing of left and right variables will affect the magnitude of the performance parameter in this case study, the top mount force. An improved model could incorporate the effects of variability on both front suspensions, but the number of iterations may need to increase to include more random events.

Both the ADAMS and simplified models are constrained at the top mount. This means that the top mount force predicted does not include the body mass inertia, i.e. the top mount is not allowed to move. In reality floating body inertia applies, therefore including the force due to acceleration at centre of gravity will result in a more accurate model. A Runge Kutta algorithm can solve the simplified model with mass acceleration included.

In the models discussed, the parts are assumed rigid. Ignoring the flexibility of the top mount plate, subframe and lower control arm could introduce uncertainty to the top mount force predicted as these are not fully rigid as assumed. The inclusion of flexible parts is feasible in ADAMS by importing an external FEA modal neutral file, .mnf or by automatically creating discrete parts with basic shapes in ADAMS/View. Medepalli [28] illustrated improvements in load predictions using a flexible frame compared with a rigid frame when correlated to experimental measurements. 
Damper strut variation is not measured due to limited component availability, therefore its variation information is based on expert opinion. Variability in stiffness and damping properties of the bush at the top mount are also assumed from drawing specifications. These design variables are similar in the assumed and measured variable data sets. The assumption of normal distributions may be inadequate, as some variables are naturally skewed and bounded. As seen in Figure 4 the best-fit distribution for jounce stiffness was a 3-parameter Weibull. In view of the small sample sizes, these variables were modelled by their equivalent normal distributions in this paper. The use of proper distribution types to describe variables could result in better characterisation of variability associated with each variable.

Also, increasing the sample size in the LHS (100 in this analysis) will improve the results from the probabilistic model, as more random combinations are accounted for. Increasing the number of samples evaluated will produce a smoother histogram and therefore errors in fitting the best-fit distribution could be minimised. Methods for testing goodness of fit, e.g. chisquare, Anderson-Darling, Kolmogorov-Smirnov [29] could be used to minimise errors in distribution-fitting and to determine the best-fit for the set of data. The only drawback is the amount of time and resources required to run a large number of simulations. Numerical integrations used in solving differential equations also introduce some truncation and round off errors [3].

\subsubsection{Simplified Model}

There is a significantly smaller number of DOF in the simplified model, which means the model will not have accounted for the dynamics of all components in the suspension unit. The commonly used lumped parameter model could be improved by using a reduced order model 
with equivalent parameters proposed by [30]. In the ADAMS model, RLD from 3 principal directions are applied at both wheel spindles. But, the simplified model in this case study includes only the vertical load transfer, therefore strut inclination is not modelled. This is about $5^{\circ}$ (the highest) in the y-z plane in equilibrium position and the angle will increase with increase in positive vertical wheel travel. Kim [31] discusses this and other effects of the suspension structure on accuracy of simplified quarter car suspension model.

In order that both roll, pitch and floating body effects are modelled, the simplified full car model should consist of 7 DOF [32]. For pitching effects only, a 5 DOF beam element representing sprung mass with front and rear suspension unit masses can be analysed. Nonlinearity in model parameters such as damping characteristics, jounce bumper static force and rebound bumper static force are approximated with $6^{\text {th }}$ degree polynomial in the simplified model. This approximation introduces some uncertainty to the model. In particular, damping characteristics could be modelled more accurately with a piecewise polynomial.

\subsection{Challenges Faced}

The selection of integrator type, maximum step size and error tolerance could affect the accuracy of simulation results. Generally, specifying smaller error tolerance will render more accurate answers but increase the time taken to run simulations as when the solution does not meet the error tolerance specified, the integrator will automatically reduce the step size and then repeat the step. It is possible to explicitly specify a maximum step size that the solver can attempt to minimise errors [33]. Reducing both error tolerance and step size will increase the simulation time significantly and these have to be traded-off with the accuracy of the results. 
This poses difficulty especially in probabilistic design where a large number of random systems are simulated.

Experience learnt from this case study is that controlling error is difficult for a combination of systems as the system dynamics change with parameter variations. Some integration error is still observed in some of the pseudo-random systems. In probabilistic analysis, these systems with observed unrealistic extreme peaks could be subsequently filtered out given that the number of systems simulated is still representative of its population statistics. In the ADAMS model simulations, 4 out of 100 systems contained integration errors and are excluded in further probabilistic analyses. The full 100-system simulations in ADAMS takes about 4 hrs to complete on a Pentium $41.8 \mathrm{GHz}$ processor, for a $10 \mathrm{~s}$ duration simulated. The same number of systems in the simplified model simulated in VB requires only a few seconds.

The integration error resulting in extreme peaks is important to control in DOE analyses. If such errors are not minimised in DOE, the parametric model resulted may be invalid or erroneous because these errors are included in the fitted model. The sensitivity results will not be accurate and may be misleading. In this case study DOE analysis, the time required to execute 256 runs ranges from 6 hrs to 2 days depending on integrator type, error tolerance and step size specified, which also affects the accuracy of the results obtained.

One of the challenges anticipated is the difficulty in collation of statistical data due to scarcity and lack of information published. Few examples of publication in engineering have been observed to include statistical variation information, others generally ignore this type of information (even though they may have been collected by the authors) [15]. In this case 
study, the first assumption of variability from several sources proved to be consistent with the measured data.

\section{CONCLUDING REMARKS}

Due to pressure to reduce product development time and cost, there is an increasing need to replace time consuming and expensive prototype testing with computational simulations. But until the uncertainties in design simulation may be characterised effectively in a systematic manner, complete virtual modelling of products cannot be achieved. Uncertainty characterisation in both data and model representations is crucial to improve confidence in analytical and computational models. This paper reported a case study evaluated as part of the effort in developing a framework for uncertainty characterisation in design simulation, using a systematic approach in recording uncertainty in data and model representations.

The new and emerging opportunity for the application of probabilistic design is also seen especially in automotive engineering to facilitate improved understanding of the effects of variability in data representation on the uncertainties in the predicted results. The benefits of probabilistic designing include the assessment of a large number of possible system configurations, to include random effects which may not have been observed with nominal systems. As current sign-off of vehicles is frequently based on very limited number of prototype tests, a probabilistic model will help assess, more confidently, the safety margins in such decisions [34]. Since durability of a vehicle depends on the design geometry, the material properties and the loading environment, it is important to understand the effects of variations in design parameters on the system responses. The load predictions from these systems can then be fed into FEA models, which predict stresses and strains for fatigue 
analyses. Definition of loads in service for new variant vehicles are often estimated from measurements on existing system, and propagated through MBS models representing the dynamics of the variant system to predict the loads from the suspension system into the body. Methodology for estimating the likely effects of variability on the estimated loads into the body is required for improved confidence in the virtual modelling results. A detailed description of parameter uncertainties on dynamic problems could be found in [35].

A breakthrough case study of a complex analysis of suspension dynamics was used to illustrate the propagation of uncertainty through models of different complexity using probabilistic methods, where the concept involved is generally applicable and should not be limited to this case only. The user could use any appropriate performance parameters and transfer functions in their respective design analyses with the probabilistic design methods. It has been shown that both simplified and ADAMS models predict the pattern of top mount force well, with the simplified model having a greater systematic shift from the experimental measurement. Owing to the lack of knowledge of the actual PDF of the response in physical system, results were compared to an experimental point to give an indication of the magnitudes of uncertainties associated with the models. For improved uncertainty modelling, evidence of the single experimental system configuration should be determined from physical tests or measurements or with more physical systems measured experimentally. Sensitivity analysis and response surface approximation, for instance, are useful for parametric studies for new variants of a system studied and rapid variance analysis can be useful for data collection and identification of key random variables to the problem. A systematic way to characterise such uncertainties information in product evaluation will be useful to facilitate future variant designs and to improve confidence and reliability in analytical and computational methods, ultimately reducing the need for prototype testing. 
A process map of probabilistic design for optimised implementation is to be produced where the use of appropriate models and probabilistic techniques may be identified. For optimised application, a simplified model could be used in initial design iterations for faster evaluations to obtain sensitivity measures to assess impact of design changes and guidance for data collection effort. At later design stages, more complex models with probabilistic methods could be used to obtain more accurate predicted results. The confidence in probabilistic models will suggest if virtual simulation could fully replace prototype testing or needs improvement. Further work involves derivation of a process model to support a procedural probabilistic design to capture uncertainties in analytical functions used to systematically record characterised uncertainty in order to aid engineers in future applications of probabilistic analysis.

\section{Acknowledgements}

The authors are greatly indebted to Dr. J. Devlukia and Mr. A. D’Cruz (Land Rover, Gaydon) for their active participation in this project, and for providing computational models, road load data and components for experimental testing.

\section{References}

1. Hudi, J., Prokop, G., Pausch, M. \& Kvasnicka, P. (2001) "Integrated Application of Multibody Simulation in the Product-Development Process”. North American MDI User Conference, June 19-20, Novi, MI, Paper No. 9352.

2. Bury, K. V. Statistical Models in Applied Science, 1975 (John Wiley \& Sons, NY).

3. Riha, D. S., Thacker, B. H., Enright, M. P., Huyse, L., Fitch, S. H. K. (2002) "Recent Advances of the NESSUS Probabilistic Analysis Software for Engineering Applications”. 
Proc. AIAA/ASME/ASCE/AHS/ASC $42^{\text {nd }}$ Structures, Structural Dynamics, and Materials (SDM), Denver, Colorado, April 22-25, Paper No. AIAA-2002-1268.

4. Hanson, K. M. \& Hemez, F. M. A framework for assessing confidence in computational predictions. Experimental Techniques, 2001, 25, 50-55.

5. Wojtkiewicz, S. F., Eldred, M. S., Field, Jr., R.V., Urbina, A. \& Red-Horse, J. R. (2001) “Uncertainty Quantification In Large Computational Engineering Models”, Proc. 42nd AIAA/ASME/ASCE/AHS/ASC Structures, Structural Dynamics, and Materials Conference, Seattle, WA, April 16-19, Paper No. AIAA-2001-1455.

6. Oberkampf, W. L., DeLand, S. M., Rutherford, B. M., Diegert, K. V. \& Alvin, K. F. Error and Uncertainty in Modelling and Simulation. Reliability Engineering and System Safety, 2002, 75, 333-357.

7. Hills, R. C. \& Trucano, T. G. Statistical validation of engineering and scientific models with application to CTH, 2001 (Sandia National Laboratories, SAND2001-0312).

8. Coleman, H. W. Some observations on uncertainties and the verification and validation of a simulation. Journal of Fluids Engineering, 2003, 125, 733-735.

9. Oakley, J. and O'Hagan, A. Bayesian inference for the uncertainty distribution of computer model outputs. Biometrika, 2002, 89, 769-784.

10. Bae, H. \& Grandhi, R. V. Uncertainty quantification of structural response using evidence theory. AIAA Journal, 2003, 41 (10), 2062-2068.

11. Kim, S. A Subsystem Synthesis Method for Efficient Vehicle Multibody Dynamics. Multibody System Dynamics, 2002, 7, 189-207.

12. MSC.ADAMS Product Catalog, 2002 (MSC.Software Corporation, Santa Ana, California, USA).

13. Wolfgang, M. Road Vehicle Suspensions, 1999 (Professional Engineering Publishing, UK). 
14. Booker, J. D., Raines, M. \& Swift, K.G. Designing Capable and Reliable Products, 2001 (Butterworth-Heinemann, UK).

15. Swift, K. G., Raines, M. \& Booker, J. D. Advances in probabilistic design: manufacturing knowledge and applications. Proc. Instn Mech Engrs., Part B, 2001, 215, 297-313.

16. Zhang, J., Kikuchi, N., Li, V., Yee, A. \& Nusholtz, G. Constitutive Modeling of Polymeric Foam Material Subjected to Dynamic Crash Loading. International Journal of Impact Engineering, 1998, 21 (5), 369-386.

17. Gibson, L. J. \& Ashby, M. F. Cellular Solids: structure and properties, $2^{\text {nd }}$ Edition, 2001 (The Press Syndicate of the University of Cambridge, UK).

18. Jones, D. I. G. Handbook of Viscoelastic Vibration Damping, 2001 (John Wiley \& Sons, UK).

19. Singh, R., Davies, P. \& Bajaj, A. K. (2001) "Nonlinear Modelling and Identification of the Dynamic Behaviour of Polyurethane Foam”. Proc. 2001 ASME DETC, Pittsburgh, PA, Sept. 9-12, 2001, Paper No. DETC2001/VIB-21592.

20. Schuëller, G. I. \& Stix, R. A Critical Appraisal of Methods to Determine Failure Probabilities. Structural Safety, 1987, 4, 293-309.

21. Bucher, C. G. Adaptive Sampling - An Iterative Fast Monte Carlo Procedure. Structural Safety, 1988, 5, 119-126.

22. Hall, P. Antithetic resampling for the bootstrap. 1989, Biometrika, 76 (4), 713-724.

23. McKay, M. D., Beckman, R. J. \& Conover, W. J. A Comparison of Three Methods for Selecting Values of Input Variables in the Analysis of Output from a Computer Code. Technometrics, 1979, 21 (2), 239-245. 
24. Helton, J. C. \& Davis, F. J. Latin Hypercube Sampling and the Propagation of Uncertainty in Analyses of Complex Systems, 2002 (Sandia National Laboratories, SAND2001-0417).

25. Iman, R. L. \& Conover, W. J. A Distribution-Free Approach to Inducing Rank Correlation Among Input Variables. Communications in Statistics, 1982, B11 (3), 311334.

26. Box, G. E. \& Draper, N. R. Empirical Model-Building and Response Surfaces, 1987 (John Wiley \& Sons, USA).

27. Myers, R. H. \& Montgomery, D. C. Response Surface Methodology: Process and Product Optimization Using Designed Experiments, 1995 (John Wiley \& Sons, USA).

28. Medepalli, S. \& Rao, R. Prediction of Road Loads for Fatigue Design - A sensitivity study. Journal of Vehicle Design, 2000, 23 (1), 161-175.

29. Kottegoda, N. T. \& Rosso, R. Statistics, Probability, and Reliability for Civil and Environmental Engineers, 1998 (McGraw-Hill, Singapore).

30. Kim, C. \& Ro, P. I. Reduced-order Modeling and Parameter Estimation for a Quarter-car Suspension System. Proc. Instn Mech Engrs., Part D, 2000, 214, 851-864.

31. Kim, C., Ro, P. I. \& Kim, H. Effect of the Suspension Structure on Equivalent Suspension Parameters. Proc. Instn Mech Engrs., Part D, 1999, 213, 457-470.

32. Kim, C. \& Ro, P. I. An Accurate Full Car Ride Model using Model Reducing Techniques. Journal of Mechanical Design, 2002, 124, 697-705.

33. Using ADAMS/Solver, 2002 (Mechanical Dynamics, Inc., Ann Arbor, Michigan, USA).

34. Personal communication, Devlukia, J., 2004, Land Rover, Gaydon.

35. Ibrahim, R. A. Structural Dynamics with Parameter Uncertainties. Applied Mechanics Review, 1987, 40 (3), 309-329. 